\title{
A Quantitative Single-cell Flow Cytometry Assay for Retrograde Membrane Trafficking Using Engineered Cholera Toxin
}

Mariska S. Simpson ${ }^{1,2, \#, ~ W a y n e ~ I . ~ L e n c e r 2, ~ 3, ~ * ~ a n d ~ P h i ~ L u o n g ', ~ * ~}$

\author{
${ }^{1}$ Graduate School of Life Science, Utrecht University, Utrecht, the Netherlands; ${ }^{2}$ Department of \\ Pediatrics, Harvard Medical School and Division of Gastroenterology, Boston Children's Hospital, \\ Boston, MA 02115, USA; ${ }^{3}$ Harvard Digestive Disease Center, Harvard Medical School, Boston, MA \\ 02115, USA
}

*For correspondence: wayne.lencer@childrens.harvard.edu; phi.luong@childrens.harvard.edu

\begin{abstract}
[Abstract] The organization and distribution of proteins, lipids, and nucleic acids in eukaryotic cells is an essential process for cell function. Retrograde trafficking from the plasma membrane to the Golgi and endoplasmic reticulum can greatly modify cell membrane composition and intracellular protein dynamics, and thus typifies a key sorting step. However, methods to efficiently quantify the extent or kinetics of these events are currently limited. Here, we describe a novel quantitative and effectively realtime single-cell flow cytometry assay to directly measure retrograde membrane transport. The assay takes advantage of the well-known retrograde trafficking of cholera toxin engineered with splitfluorescent proteins to generate novel tools for immediate monitoring of intracellular trafficking. This approach will greatly extend the ability to study the underlying biology of intracellular membrane trafficking, and how trafficking systems can adapt to the physiologic needs of different cell types and cell states.
\end{abstract}

Keywords: Retrograde membrane transport, Golgi, Endoplasmic reticulum, Split fluorescent protein, Cholera toxin, Flow cytometry

[Background] All eukaryotic cells depend on their ability to dynamically sort and sequester molecules to membrane-bound subcellular organelles for organization and distribution to specific regions of the cell. An essential step in this process is the early sorting endosome and trans-Golgi network (TGN). Among other trafficking pathways that emerge from the sorting endosome, retrograde trafficking via the secretory pathway to the TGN typifies a key sorting step (Johannes and Popoff, 2008). Cell membrane proteins and lipids undergo retrograde trafficking. Further retrograde trafficking from the TGN all the way to the endoplasmic reticulum (ER) can be completed by some plasma membrane lipids and can cleverly be co-opted by several bacterial toxins and viruses to cause disease (Cho et al., 2012; Personnic et al., 2016; Williams and Tsai, 2016).

Previous biochemical assays measured sulfation and $\mathrm{N}$-glycosylation of toxin as an indication of entry into the TGN and ER, respectively (Rapak et al., 1997; Falguieres et al., 2001; De Luca and Lencer, 2006). These biochemical assays, and alternatively the use of ultrastructural electron and confocal light microscopy, have proven to be highly informative (Sandvig et al., 1992; Torgersen et al., 2001; Chinnapen et al., 2012). However, these approaches can be laborious, have poor dynamic range and 
are difficult to quantify with precision.

It is well established that $A_{5}$ bacterial toxins undergo endocytosis and retrograde transport to enter the TGN and ER (Lencer and Tsai, 2003). Cholera toxin (CTx) which typifies the $A B_{5}$ toxin family, consists of an individual catalytic A subunit (CTA) that includes the CTA1 and CTA2 subregions. CTA is non-covalently associated with the homopentameric $B$ subunits (CTB) through CTA2 subregion. CTB binds the glycosphingolipid GM1 receptor at the plasma membrane and initiates endocytosis. Following endocytosis, CTx enters the ER via retrograde transport. Here, the enzymatically active CTA1-chain dissociates and undergoes retro-translocation to escape the ER and enter the cytosol. Once in the cytosol, the CTA1-chain refolds and activates adenyl cyclase to cause disease. Meanwhile, the CTA2chain remains assembled with the B-subunit in the ER lumen.

We took advantage of CTx's structural features that underlie retrograde trafficking to develop a novel quantitative, sensitive and near real-time single-cell flow cytometry assay. The assay depends on CTB's ability to bind GM1 at the cell membrane and the C-terminal KDEL-motif of the CTA2-chain's ability to bind the ER-retention KDEL-receptor (Lencer and Tsai, 2003). Additionally, we applied the split fluorescent protein (spilt-FP) technologies to CTx for single-cell flow cytometry (Feng et al., 2017; Luong et al., 2020). The CTA2 chain was engineered to include the split monomeric neon green2 (mNG2 ${ }_{11}$ ) peptide and was coexpressed in E. coli with the homopentameric CTB. The assembled CTA2-mNG2 ${ }_{11}$ chain associated with the CTB pentamer was purified, hereon called CTB-mNG2 ${ }_{11}$ (Figure 1A).

A

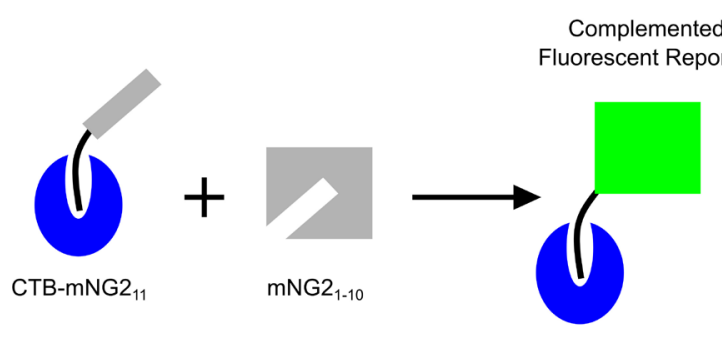

B
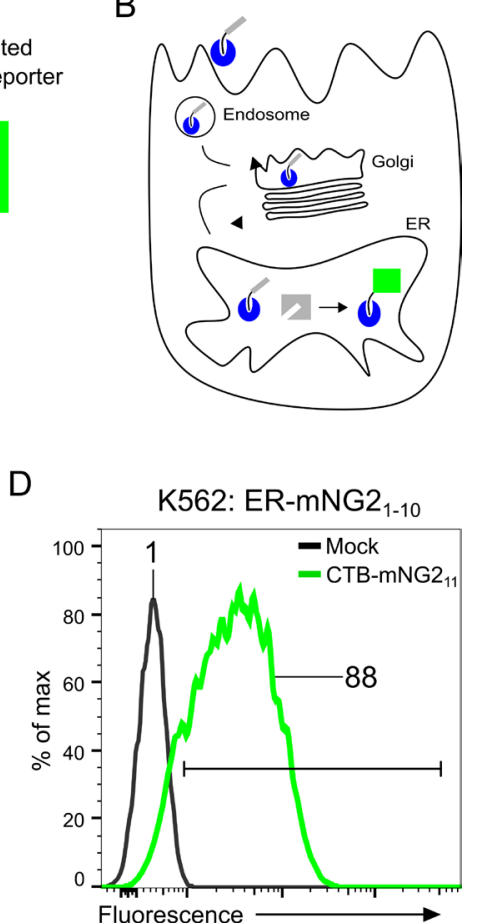

C

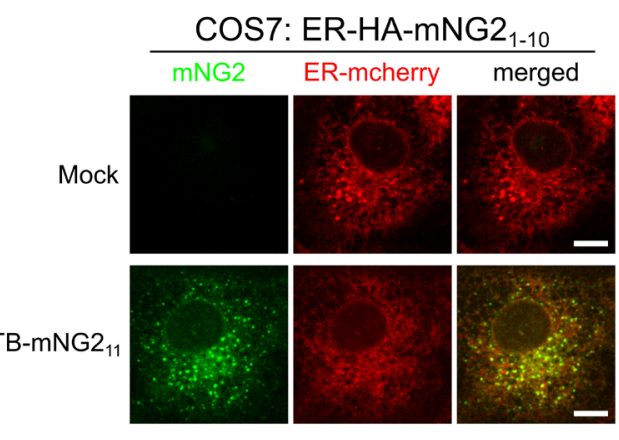

Figure 1. Split-fluorescent toxin reporter for retrograde trafficking. A. Cartoon schematic of split-fluorescent toxin reporter strategy. The CTA2-mNG2 ${ }_{11}$ strand (black-gray) is assembled noncovalently to cholera toxin B subunit (CTB, blue) to recombinantly produce the CTB-mNG2 11 toxin reporter. Complementation of CTB-mNG211 with $m N G 2_{1-10}$ produces green fluorescence. $B$. 
Retrograde trafficking of CTB-mNG211 and complementation of ER-localized mNG21-10. ERlocalized complementation generates a green fluorescent signal. C. Confocal microscopy of CTBmNG2 11 retrograde trafficking to the ER in COS7 cells stably expressing ER-mcherry and HA-tagged ER-HA-mNG21-10. Cells were incubated with CTB-mNG2 11 for $6 \mathrm{~h}$. Scale bar $=10 \mu \mathrm{m}$. C. Flow cytometry graph of relative fluorescence intensities of retrograde trafficking from the plasma membrane to the ER. K562 cells stably expressing K562-ER-HA-mNG21-10 were Mock or CTB$\mathrm{mNG}{ }_{11}$ treated for $5 \mathrm{~h}$ and assayed by flow cytometry.

The assay also requires cell-lines of interest to stably express the complementary portion of the split neon green2 fragment ( $\mathrm{mNG}_{1-10}$ ) into organelle compartments of the retrograde pathway. We recently engineered reporter systems to monitor retrograde trafficking from the plasma membrane into the TransGolgi Network (TGN) and also the Endoplasmic Reticulum (ER) (Luong et al., 2020). Various cell lines including adherent epithelial cells (e.g., human embryonic kidney (HEK 293T) and African Green Monkey kidney COS7) and cells grown in suspension (e.g., human lymphocyte K562 cells) have been validated for retrograde TGN and ER retrograde trafficking (Luong et al., 2020). Some cell lines may not have GM1 lipid and thus will normally not be suitable for the toxin reporter assay. Insufficient GM1 expression can be adapted for the assay by pre-incubating cells with exogenous GM1 containing short C12:0 acyl chain in the ceramide domains (GM1-C12:0) for integration into the membrane (Chinnapen et al., 2012). Here we describe the utilization of ER-HA-mNG21-10 which encodes the signal sequence from the ER chaperone BIP at the N-terminal and C-terminal KDEL-motif for localization to the ER. The membrane tethered Sec61 $\beta$-HA-mNG21-10 construct (mNG21-10 fused with ER-resident protein Sec61 $\beta$ ) can also be used to monitor ER retrograde trafficking. Following the addition of CTB-mNG2 11 to the stably expressing cell lines, the toxin will bind the GM1 receptor and undergo endocytosis and retrograde transport. Once it reaches the ER, the mNG2 11 fragment of CTB-mNG2 11 will complement with the mNG21-10 portion of ER-HA-mNG21-10, (alternatively with Sec61ß-HA-mNG21-10). The resulting complementation will emit a fluorescence signal and can be assessed by confocal microscopy or flow cytometry to quantify the extent and kinetics of retrograde transport. Kinetic time course experiments on retrograde trafficking across diverse conditions and cell lines can be reliably quantified by flow cytometry. Notably, we obtained high levels of reproducibility in K562 cells with calculated Z-factors of 0.92 and 0.96 for TGN and ER transport, respectively (Luong et al., 2020). A Z-factor $>0.5$ is considered ideal for high-throughput screening (Zhang et al., 1999). Hence, this approach can be applied in high throughput for gene or small molecule profiling and discovery to address trafficking at a system-wide level.

\section{Materials and Reagents}

Note: With the exception of the listed plasmids, the following reagents can be interchanged with appropriate alternative options.

1. Pipette tips (USA Scientific, catalog numbers: 1180-3810, 1180-1810, 1180-8810, 1126-7810) 
2. Disposable plastic serological pipets (Corning, catalog numbers: $4487,4488,4489,4490$ )

3. 6-well clear TC-treated multiple well plates (Corning, Costar ${ }^{\mathrm{TM}}$, catalog number: 3506 )

4. 12-well clear TC treated multiple well plate (Corning, Costar ${ }^{\mathrm{TM}}$, catalog number: 3513 )

5. 24-well clear TC treated multiple well plate (Corning, Costar $^{\mathrm{TM}}$, catalog number: 3526 )

6. 96-well Deep Well Block (Fisher Scientific, catalog number: 12566611)

7. Axygen PCR 8-strip clear tubes (Fisher Scientific, catalog number: 14222251)

8. Coverslips (Fisher Scientific, catalog number: NC9455457)

9. Microscope slides (Fisher Scientific, catalog number: 22034486)

10. Econo-Pac Chromatography Column (Bio-Rad, catalog number: 7321010)

11. SnakeSkin 3.5K MWCO Dialysis Tubing (Thermo Scientific ${ }^{\top M}$, fisher scientific, catalog number: PI88242)

12. HiTrap SP HP column (Sigma-Aldrich, GE Healthcare, catalog number: GE17-1151-01)

13. Inoculating loops (Fisher Scientific, BD Difco ${ }^{\mathrm{TM}}$, catalog number: 22-031-22)

14. Petri dishes with clear lid (Fisherbrand ${ }^{\mathrm{TM}}$, Fisher Scientific, catalog number: FB0875712)

15. Internally threaded cryogenic vials (Corning ${ }^{\mathrm{TM}}$, Fisher Scientific, catalog number: 03-374-059)

16. Seal-Rite ${ }^{\circledR} 1.5 \mathrm{ml}$ microcentrifuge tubes (USA Scientific, catalog number: 1615-5510)

17. $15 \mathrm{ml}$ centrifuge tube (Corning ${ }^{\circledR}$, catalog number: 430052)

18. $50 \mathrm{ml}$ centrifuge tube (Corning ${ }^{\circledR}$, catalog number: 430897)

19. General purpose syringe BD Luer-Lok ${ }^{\mathrm{TM}} 5 \mathrm{ml}$ (Becton Dickinson, McKesson, catalog number: 309646)

20. Millex-HV syringe filter unit, $45 \mu \mathrm{m}$, PVDF, $33 \mathrm{~mm}$, gamma sterilized (Millipore, Millipore Sigma, catalog number: SLHV033RS)

21. Falcon ${ }^{\mathrm{TM}}$ Round-Bottom polystyrene tubes (Corning, Fisher Scientific, catalog number: 352008 )

22. Brand ${ }^{\mathrm{TM}}$ Plastic Cuvettes (BrandTech ${ }^{\mathrm{TM}}$, Fisher Scientific, catalog number: 759075D)

23. Samco ${ }^{T M}$ Transfer pipettes (Thermo Scientific ${ }^{T M}$, catalog number 20220S)

24. Cell culture treated flask (Corning ${ }^{\mathrm{TM}}$, catalog number: 430639)

25. Falcon ${ }^{\mathrm{TM}}$ test tube with cell strainer snap cap (Corning ${ }^{\mathrm{TM}}$, Fisher Scientific, catalog number: 08771-23)

26. Milli-Q water

27. CTB pET28a (Addgene, plasmid ID: 141166)

28. mNG211-CTA2 pGEXTEV-SUMO (Addgene, plasmid ID: 141167)

29. ER-HA-mNG21-10EF1a-pHAGE-IRES-blasticidin (Addgene, plasmid ID: 141165)

30. Sec61ß-HA-mNG21-10 Ef1a-pHAGE-IRES-blasticidin (Addgene, plasmid ID: 141213)

31. GM1-C12:0 (see Chinnapen et al., 2012)

32. Cholera toxin subunit B (recombinant), Alexa Fluor ${ }^{\mathrm{TM}} 488$ conjugate (Thermo Fisher, catalog number: C34775)

33. Shuffle ${ }^{\circledR} T 7$ Express Competent E. coli (New England BioLabs, catalog number: C3029J)

34. SOC medium (Corning ${ }^{\mathrm{TM}}$, Fisher Scientific, catalog number: 46003CR)

35. Miller's Luria Agar Powder (Research Product International, catalog number: L24022) 
36. Miller's LB Broth Granulated (Fisher BioReagents ${ }^{\mathrm{TM}}$, Fisher Scientific, catalog number: BP9723)

37. Ampicillin Sodium Salt, Crystalline Powder (GoldBio, catalog number: A301100)

38. Kanamycin (GoldBio, catalog number: K12050)

39. BD Difco ${ }^{\mathrm{TM}}$ Dehydrated Culture Media $2 \mathrm{x}$ Yeast extract Tryptone (2x YT) medium (Fisher BioReagents ${ }^{\mathrm{TM}}$, Fisher Scientific, catalog number: DF0440)

40. Isopropyl-beta-D-thiogalactoside (IPTG) (GoldBio, catalog number: I2481)

41. Trizma ${ }^{\circledR}$ base (Sigma-Aldrich, Millipore Sigma, catalog number: T1503)

42. Sodium chloride $\geq 99.0 \%$ (Sigma-Aldrich, Millipore Sigma, catalog number: S9888)

43. Triton ${ }^{\mathrm{TM}} \mathrm{X}-100$ (Sigma-Aldrich, Millipore Sigma, catalog number: T8787)

44. Phenylmethanesulfonyl fluoride, PMSF (Thermo Scientific ${ }^{T M}$, catalog number: 36978)

45. Glutathione Agarose resin (GoldBio, catalog number: G-250)

46. L-Glutathione reduced (Sigma-Aldrich, Millipore Sigma, catalog number: G4251)

47. ULP1 protease (produced in-house, Addgene, plasmid ID 64697)

48. Sodium phosphate dibasic, $\mathrm{Na}_{2} \mathrm{HPO}_{4}$ (Sigma, catalog number: S9763)

49. 4-20\% Mini-Protean ${ }^{\circledR}$ TGXTM Precast Gels, 10 -well, $50 \mu \mathrm{l}$ (Bio-Rad, catalog number: 4561094)

50. Precision Plus unstained protein standard (Bio-Rad, catalog number:161-0363)

51. 10x Tris Glycine SDS PAGE Buffer (national diagnostics, catalog number: EC-870)

52. Ez-Run ${ }^{\mathrm{TM}}$ Protein Gel staining Solution (Fisher BioReagents ${ }^{\mathrm{TM}}$, Fisher Scientific, catalog number: BP36201)

53. Liquid nitrogen

54. Absolute ethanol (Pharmco, catalog number: 111000200CSPP)

55. RPMI Medium 1640, GlutaMAX ${ }^{\mathrm{TM}}$-I (Thermo Fisher Scientific, catalog number: 61870)

56. Fetal Bovine Serum, qualified, One Shot ${ }^{\mathrm{TM}}$ format, heat inactivated (Thermo Fisher Scientific, catalog number: A3160602)

57. Fetal Bovine Serum, fatty acid free (Sigma-Aldrich, catalog number: A6003-10G)

58. Penicillin-Streptomycin Solution (Corning ${ }^{\mathrm{TM}}$, Fisher Scientific, catalog number: MT30002CI)

59. Trypsin-EDTA (0.25\%), phenol red (Gibco ${ }^{T M}$, Fisher Scientific, catalog number: 25-200-072)

60. Cell culture phosphate buffered saline $1 \mathrm{x}$ (Corning ${ }^{\mathrm{TM}}$, Fisher Scientific, catalog number: MT21040CV)

61. DMEM with L-glutamine, $4.5 \mathrm{~g} / \mathrm{L}$ glucose and sodium pyruvate (Corning ${ }^{\mathrm{TM}}$, Fisher Scientific, catalog number: MT10013CV)

62. Lentivirus packaging plasmids psPAX2 (Addgene, plasmid ID: 12260)

63. Lentivirus packaging plasmids pVSVG (Addgene, plasmid ID: 8454)

64. Polyethylenimine, PEI (Fisher Scientific catalog number: NC1014320)

65. Polybrene (Santa Cruz Biotechnology, catalog number: sc134220)

66. Blasticidin (GoldBio, catalog number: B800)

67. ER-mCherry plasmid (available on request)

68. Anti-HA antibody (Sigma-Aldrich, Millipore Sigma, catalog number: 11867423001)

69. Anti-Golgin97 (Thermo Fisher, catalog number: A21270) 
70. Appropriate secondary antibody (Invitrogen, catalog numbers: A21247 and A11001)

71. 20\% paraformaldehyde aqueous solution (Electron Microscopy Science, Fisher Scientific, catalog number: 15713S)

72. Saponin (Sigma-Aldrich, Millipore Sigma, catalog number: 47036)

73. Normal Goat serum (Sigma-Aldrich, Millipore Sigma, catalog number: G902310)

74. Coomasie blue (Fisher Bioreagents ${ }^{\mathrm{TM}}$, EZ-run ${ }^{\mathrm{TM}}$, catalog number: BP36201)

75. Collagen (Sigma-Aldrich, catalog number: C7661)

76. FluorSave mountant (Millipore, catalog number: 345789)

77. $100 \mathrm{mg} / \mathrm{ml}(1,000 \mathrm{x})$ ampicillin stock (see Recipes)

78. $50 \mathrm{mg} / \mathrm{ml}(1,000 \mathrm{x})$ kanamycin stock (see Recipes)

79. LB agar plate (see Recipes)

80. LB media (see Recipes)

81. $2 x$ YT media (see Recipes)

82. 1 M IPTG stock solution (see Recipes)

83. $50 \%$ glycerol (see Recipes)

84. Triton X-100 lysis buffer (see Recipes)

85. Binding buffer (see Recipes)

86. Elution buffer (see Recipes)

87. Dialysis Buffer (see Recipes)

88. Buffer A (see Recipes)

89. Buffer $B$ (see Recipes)

90. K562 cell media (see Recipes)

91. HEK 293T and COS7 cell media (see Recipes)

92. Blasticidin stock (see Recipes)

93. 4\% paraformaldehyde (PFA) (see Recipes)

94. $0.2 \%$ saponin (see Recipes)

95. FACS Buffer (see Recipes)

\section{Equipment}

Note: The following equipment brand and manufacturers are suggestions and can be interchanged with appropriate alternative options.

1. Micropipettes (Gilson, catalog number: F167360)

2. Pipette aid (Drummond Scientific, catalog number: 4-000-102)

3. Appropriate personal protective equipment

4. $250 \mathrm{ml}$ conical flask (Sigma, catalog number: CLS5100250)

5. $2 \mathrm{~L}$ conical flask (Sigma, catalog number: CLS51002L)

6. Magnetic stirring bar (Fisher Scientific, Fisherbrand ${ }^{\mathrm{TM}}$, catalog number: 14-513-52)

7. Magnetic stirrer (Thermolyne Nuova, catalog number: Z110930) 
8. Vortex mixer (Fisher Scientific, Vortex-Genie ${ }^{\mathrm{TM}} 2$, catalog number: 15557335)

9. Heat block (Benchmark Scientific, catalog number: BSW1500)

10. Autoclave

11. Tabletop incubator (Barnstead Lab Line 100)

12. Centrifuge capable of spinning $500 \mathrm{ml}$ bottles (Thermo Scientific, Sorvall Lynx 4000 , catalog number: 75006580 )

13. $500 \mathrm{ml}$ centrifuge bottles (Fisher Scientific, catalog number: 05-564-2)

14. Emulsiflex $\mathrm{C} 5$ homogenizer (Avestin, catalog number: EF-C5)

15. Tabletop microcentrifuge (Eppendorf, catalog number: 12843222)

16. Platform Shaker at $4{ }^{\circ} \mathrm{C}$ (Orbital Shaker)

17. Stericup-GP Vacuum Filtration System (Millipore, Millipore Sigma, catalog number: SCGPU05RE)

18. NanoDrop 2000 (Thermo Scientific ${ }^{T M}$, catalog number: ND-2000)

19. NGC Quest ${ }^{\top \mathrm{M}} 10$ Plus Chromatography system (Bio-Rad, catalog number: 7880003)

20. Azure $\mathrm{C} 300 \mathrm{gel}$ imaging system (Azure biosystem)

21. Cell culture incubator (Thermo Fisher Scientific, Forma ${ }^{T M}$ Series II, catalog number: 3110 )

22. Biosafety cabinet (Labcult)

23. Water bath

24. Spectrophotometer

25. $\mathrm{pH}$ meter

26. Electrophoresis chamber (Bio-Rad, Mini-PROTEAN tetra)

27. Powerpack (Bio-Rad, Powerpac ${ }^{\mathrm{TM}}$ universal power supply, catalog number: 1645070)

28. $-20^{\circ} \mathrm{C}$ freezer

29. $-80^{\circ} \mathrm{C}$ freezer

30. BD LSRFortessa ${ }^{\mathrm{TM}}$ Flow cytometer system (BD biosciences)

31. Spinning disk confocal head coupled to an inverted Zeiss Axiovert 200M microscope

\section{Software}

Note: Equivalent software can be used.

1. Chromlab ${ }^{\mathrm{TM}}$ Software $6.0 \quad$ (Bio-Rad, https://www.bio-rad.com/en-us/product/chromlabsoftware?ID=MFCVPXIVK)

2. GraphPad Prism Software version 8.0 (https://www.graphpad.com)

3. BD FACSDiva ${ }^{\mathrm{TM}}$ Software (BD, https://www.bdbiosciences.com/en-us/instruments/researchinstruments/research-software/flow-cytometry-acquisition/facsdiva-software)

4. FlowJo ${ }^{\mathrm{TM}}$ Software v10.6.2 (BD, https://www.flowjo.com)

5. Excel (Microsoft Corporation, https://www.microsoft.com/Microsoft/Excel)

6. Zeiss Axiovert 200M microscope, spinning disk confocal head 


\section{Procedure}

A. Protein purification

1. Cholera toxin $B$ subunit (CTB) is cloned into a pET28a vector (Clontech). $m N G 211$ is fused to cholera toxin A2 strand and cloned into PGEXTEV-SUMO vector. The construct contains an $\mathrm{N}$ terminal GST tag to facilitate purification of CTB-mNG2 ${ }_{11}$ and a SUMO protease cleavage site to allow removal of the GST-SUMO tag.

2. Perform co-transformation of CTB pET28a and mNG2 ${ }_{11}-\mathrm{CTA} 2 \mathrm{pGEXTEV-SUMO}$ plasmids into Shuffle T7 Express E. coli according to manufacturer's High Efficiency Transformation protocol. Dilute transformed bacteria in SOC (typically 1:10) and spread 50-100 $\mu \mathrm{l}$ on a prewarmed LB agar plate (containing $100 \mu \mathrm{g} / \mathrm{ml}$ ampicillin, $50 \mu \mathrm{g} / \mathrm{ml}$ kanamycin).

3. Grow transformed Shuffle T7 Express cells for $16-24 \mathrm{~h}$ on an LB agar in a $30^{\circ} \mathrm{C}$ incubator.

4. The next day, restreak the transformed cells onto a new an LB agar plate (containing $100 \mu \mathrm{g} / \mathrm{ml}$ ampicillin, $50 \mu \mathrm{g} / \mathrm{ml}$ kanamycin) and regrow overnight at $30^{\circ} \mathrm{C}$.

5. Inoculate $100 \mathrm{ml} 2 x$ YT (supplemented with $100 \mu \mathrm{g} / \mathrm{ml}$ ampicillin, $50 \mu \mathrm{g} / \mathrm{ml}$ kanamycin) and incubate for $3-5 \mathrm{~h}$ at $35^{\circ} \mathrm{C}$, shaking at $225 \mathrm{rpm}$.

Note: Make $-80{ }^{\circ} \mathrm{C}$ glycerol stock for future use. Add $500 \mu \mathrm{l}$ of the overnight culture to $500 \mu \mathrm{l}$ $50 \%$ glycerol in a $2 \mathrm{ml}$ cryogenic vial and store at $-80{ }^{\circ} \mathrm{C}$.

6. Measure the $\mathrm{OD}_{600 \mathrm{~nm}}$ of the starter culture and inoculate a larger $500 \mathrm{ml}$ of $2 \mathrm{x}$ YT (supplemented with $100 \mu \mathrm{g} / \mathrm{ml}$ ampicillin, $50 \mu \mathrm{g} / \mathrm{ml}$ kanamycin) to obtain an initial OD $_{600 \mathrm{~nm}}$ of approximately 0.05 0.1 .

7. Incubate at $35^{\circ} \mathrm{C}$, shaking at $225 \mathrm{rpm}$ and measure $\mathrm{OD}_{600 \mathrm{~nm}}$ every $30-60$ min until $1.0-1.2$ is obtained. This should take approximately 3-5 h.

8. Induce cells by adding a final concentration of $0.4 \mathrm{mM} \mathrm{IPTG}$ and incubate for $16-20 \mathrm{~h}$ at $18^{\circ} \mathrm{C}$, shaking at $225 \mathrm{rpm}$.

9. Harvest cells by transferring culture to $500 \mathrm{ml}$ centrifuge bottle and centrifuging at 5,000 $\mathrm{xg}$ for $10 \mathrm{~min}$ at $4{ }^{\circ} \mathrm{C}$. Discard the supernatant and process the pellets as quickly as possible to minimize insoluble products. Keep the sample on ice to prevent protein degradation.

10. Resuspend pellet in $30 \mathrm{ml}$ lysis buffer by pipetting and briefly vortexing. Ensure that no pellet remains.

11. Meanwhile, prepare glutathione agarose resin:

a. Swirl container and transfer glutathione agarose resin ( $1 \mathrm{ml}$ for $8 \mathrm{mg}$ GST-tagged protein) to a $50 \mathrm{ml}$ tube.

b. Resuspend up to $30 \mathrm{ml}$ in ice-cold Milli-Q water, spin at $300 \times \mathrm{g}$ for $1 \mathrm{~min}$ at $4{ }^{\circ} \mathrm{C}$. Aspirate of Milli-Q water.

C. Resuspend up to $30 \mathrm{ml}$ in ice-cold binding buffer, spin at $300 \times \mathrm{g}$ for $1 \mathrm{~min}$ at $4{ }^{\circ} \mathrm{C}$. Aspirate of binding buffer.

d. Store washed glutathione agarose resin in $5 \mathrm{ml}$ binding buffer at $4{ }^{\circ} \mathrm{C}$ or on ice until use.

12. Homogenize cells with emulsifier: 

a. Place cooling coil on ice.
b. Add sample resuspended in lysis buffer to Avestin emulsifier.
c. Continuously homogenize sample with pressure fluctuating around 5,000 psi.

13. Transfer lysate to a $50 \mathrm{ml}$ tube and centrifuge at $15,000 \times \mathrm{g}$ for $10 \mathrm{~min}$ at $4{ }^{\circ} \mathrm{C}$ to pellet debris.

14. Transfer supernatant to a new $50 \mathrm{ml}$ tube and discard the pellet. Add washed Glutathione Resin to the cleared lysate and incubate at $4{ }^{\circ} \mathrm{C}$ for $1 \mathrm{~h}$ with gentle end-over-end rotation.

15. Transfer slurry to an Econo-Pac column and allow the sample to settle.

16. Wash beads three times each with 5 column volumes of binding buffer.

17. Elute protein by adding 5 column volumes of elution buffer directly to the glutathione agarose resin.

18. Determine protein concentration by measuring the $A_{280 n m}$ using a NanoDrop 2000 spectrophotometer. An absorbance of 1.0 unit equates to a protein concentration of $1.0 \mathrm{mg} / \mathrm{ml}$ for CTB-mNG2 11 (extinction coefficient: $58,955 \mathrm{M}^{-1} \mathrm{~cm}^{-1}$ ).

19. Add ULP1 protease to obtain a ULP1:CTB-mNG2 11 ratio of $1: 10 \mathrm{w} / \mathrm{w}$ by weight.

20. Transfer eluted protein containing ULP1 protease to a SnakeSkin Dialysis tubing as instructed by the manufacturer. Dialyze overnight at $4^{\circ} \mathrm{C}$ in $1 \mathrm{~L}$ Dialysis Buffer, continuously stirred.

21. Next day, discard the external buffer and dialyze for $3 \mathrm{~h}$ at $4^{\circ} \mathrm{C}$ in $1 \mathrm{~L}$ Buffer $\mathrm{A}$, continuously stirred.

22. Collect the dialyzed protein and filter through a $0.45 \mu \mathrm{m}$ filter unit into a new $50 \mathrm{ml}$ tube.

23. Perform cation exchange using Hi-Trap SP HP column according to the manufacturer's purification protocol using continuous ionic strength gradient to elute purified protein.

a. Bio-Rad NGC Quest10 Plus Chromatography system.

b. Load the protein onto the column pre-equilibrated with Buffer $A$ at a flow rate of $1 \mathrm{ml} / \mathrm{min}$ at $4{ }^{\circ} \mathrm{C}$ using the sample pump.

c. Wash the column with 5 column volumes of buffer $A$ at a flow rate of $1 \mathrm{ml} / \mathrm{min}$ at $4{ }^{\circ} \mathrm{C}$.

d. Elute the column with 15 column volumes of continuously increasing percentage of buffer $\mathrm{B}(0-80 \%)$ at a flow rate of $1 \mathrm{ml} / \mathrm{min}$ at $4{ }^{\circ} \mathrm{C}$. Collecte single $0.5-1 \mathrm{ml}$ fractions in $5 \mathrm{ml}$ roundbottom polystyrene tubes.

24. Load $20 \mu \mathrm{l}$ of each fraction and analyze by Tris-Glycine SDS-PAGE (see Notes) and stain the gel with Coomassie blue reagent. Molecular weight of CTB monomer $=11.6 \mathrm{kDa}$. Molecular weight of mNG2 ${ }_{11}$-CTA2 $=7.8 \mathrm{kDa}$. Recombinant GST-SUMO and ULP1 elutes in the flowthrough fractions.

Note: Visualization of CTA2-mNG2 ${ }_{11}$ can be challenging to observe by Tris-Glycine SDS-PAGE. Tris-Tricine SDS-PAGE enables better separation of small molecular weight proteins. However, it is not critical to perform this step as CTA2-NG2 ${ }_{11}$ co-elutes with CTB if purification was performed correctly.

25. Identify and combine fractions containing purified CTB-mNG211. Determine the concentration of CTB-mNG2 ${ }_{11}$ by measuring the $A_{280 n m}$ using a NanoDrop 2000 spectrophotometer.

26. Aliquots are flash-frozen using liquid nitrogen and stored at $-80^{\circ} \mathrm{C}$ for future use. Freeze- 
thawing of CTB-mNG2 11 should be minimized and small aliquots $(20-50 \mu \mathrm{l}$ recommended volume) can be distributed into PCR 8-strip tubes.

B. Lentivirus production and cell-line transduction

Note: Lentiviruses are classified as Biosafety Level 2 (BSL-2) organisms and thus appropriate measures and facilities are required to conduct experiments. Perform the following steps in a biosafety cabinet.

1. ER-HA-mNG21-10 and Sec61ß-HA-mNG21-10 constructs include a blasticidin selection marker and HA-tag for immunofluorescence detection using anti-HA primary antibody.

2. Plate HEK 293T cells in a 6-well plate to obtain $80 \%$ confluency for $24 \mathrm{~h}$ before transfection.

3. Transfect HEK 293T cells with lentivirus transfer plasmid (ER-HA-mNG21-10 or Sec61ß-HAmNG21-10), packaging plasmids (psPAX2 and pVSVG).

a. Prepare $1.5 \mu \mathrm{g} /$ well ER-HA-mNG21-10 (or Sec61ß-HA-mNG21-10), $1 \mu \mathrm{g} /$ well psPAX2, 0.5 $\mu \mathrm{g} /$ well pVSVG in $50 \mu \mathrm{l}$ Opti-MEM.

b. Prepare PEl at a ratio of 3:1 PEI:DNA in $50 \mu \mathrm{l}$ Opti-MEM.

c. Combine Opti-MEM containing plasmids and PEI together and incubate for 5-15 min at room temperature.

d. Add the PEI/plasmid mix to wells in a dropwise manner, evenly distributing the mix over the well.

4. Incubate for $4-6 \mathrm{~h}$ at $37{ }^{\circ} \mathrm{C} 5 \% \mathrm{CO}_{2}$. Aspirate the media and replace with $2 \mathrm{ml}$ fresh media (DMEM, $10 \% \mathrm{FBS}$ ). Incubate for $48 \mathrm{~h}$ at $37{ }^{\circ} \mathrm{C} 5 \% \mathrm{CO}_{2}$ to allow HEK $293 \mathrm{~T}$ cells to secrete the lentivirus into the culture media.

5. Harvest the culture media containing the secreted lentivirus and store at $4{ }^{\circ} \mathrm{C}$. Add fresh media and harvest again at $72 \mathrm{~h}$ following transfection.

6. Combine the collected culture media and filter through a $0.45 \mu \mathrm{m}$ filter. Lentivirus can be aliquoted and stored at $-80^{\circ} \mathrm{C}$ for future use.

7. Culture your cell-line(s) of interest.

a. Not all cell-lines bind Cholera Toxin. In addition, each cell line has a varying range of retrograde activity. HEK 293T, COS7 and K562 are validated lines for retrograde trafficking.

b. Determine if your cell line of interest can at least bind cholera:

i. Incubate cells with fluorescent $2 \mathrm{~nm}$ CTB-Alexa Fluor 488 for at least $30 \mathrm{~min}$ at $37^{\circ} \mathrm{C}$ $5 \% \mathrm{CO}_{2}$.

ii. Wash cells, resuspend, and assay for CTB-Alexa Fluor 488 binding by flow cytometry as described below.

Note: If cell line does not express sufficient GM1, cells can be pre-incubated with $2 \mu m$ GM1C12:0 diluted in fatty-acid free BSA for $10 \mathrm{~min}$ at $37^{\circ} \mathrm{C}$. Synthesis of GM1-C12:0 is outlined in Chinnapen et al., 2012.

c. Warm media, 1x PBS and trypsin in a water bath set to $37^{\circ} \mathrm{C}$. 
Note: We cultured K562 cells in RPMI + 10\% FBS pen/strep and HEK $293 T$ and COS7 cells in DMEM + 10\% FBS pen/strep.

8. When cells are approximately $60-80 \%$ confluent, aspirate off media, wash cells with $1 \times$ PBS, trypsinize, and resuspend in media. Split cells into a 6-well plate with each well containing $1 \mathrm{ml}$ media.

9. Transduce your cells with lentivirus:

a. Add $1 \mathrm{ml}$ virus/polybrene to a 6 -well plate containing $1 \mathrm{ml}$ media containing cells.

b. Final polybrene concentration at $5 \mu \mathrm{g} / \mathrm{ml}$ to filtered virus.

c. Incubate at $37^{\circ} \mathrm{C} 5 \% \mathrm{CO}_{2}$ for $24 \mathrm{~h}$.

10. Aspirate off media and replace with fresh growth media and incubate for an additional day. Time may vary according to how quickly cell lines recover and grow.

11. Next day collect cells in $15 \mathrm{ml}$ tube, centrifuge at $1,000 \times \mathrm{g}$ for $30 \mathrm{~s}$ and aspirate off media.

12. Resuspend cells in $5 \mathrm{ml}$ media and transfer cells to a T25 flask (or a $60 \mathrm{~mm}$ culture dish).

13. Select for transduced cells expressing ER-HA-mNG21-10 or Sec61ß-HA-mNG21-10 with blasticidin. Optimal blasticidin concentration should be predetermined by testing drug toxicity in parental cells.

a. Plate parental cells in a 6-well plate to obtain $\sim 50 \%$ confluency the next day.

b. Add final blasticidin concentrations ranging between $2 \mu \mathrm{g} / \mathrm{ml}$ and $100 \mu \mathrm{g} / \mathrm{ml}$.

c. Observe selection process to monitor the optimal concentration of blasticidin required to kill $>90 \%$ of the cells typically within 3-14 days.

d. Use the predetermined concentration for selection of transduced cells.

C. Assay validation by confocal imaging

Note: Perform the following cell culture steps in a biosafety cabinet.

1. If necessary, collagen coat coverslips. Add $150 \mu \mathrm{l}$ collagen diluted in $70 \%$ ethanol to coverslip placed in a 12-well plate. Allow to completely airdry in the biosafety cabinet.

2. Plate cells (DMEM, $10 \%$ FBS, pen/strep) on coverslips to obtain $\sim 80 \%$ confluency the next day. Incubate cells at $37^{\circ} \mathrm{C} 5 \% \mathrm{CO}_{2}$.

3. Next day replace cells with fresh growth media.

4. Treat cells with $20 \mathrm{~nm}$ CTB-mNG2 11 and incubate for $6 \mathrm{~h}$ at $37{ }^{\circ} \mathrm{C} 5 \% \mathrm{CO}_{2}$.

Note: PFA should be handled in a chemical fume hood.

5. Aspirate media, and fix cells with $1 \mathrm{ml} 4 \%$ paraformaldehyde (PFA) in 1x PBS and incubate at room temperature for 20-60 min.

6. Aspirate off PFA, wash twice with $1 \mathrm{ml} 1 \mathrm{x}$ PBS and permeabilize with $1 \mathrm{ml} 0.2 \%$ saponin $1 \mathrm{x}$ PBS.

7. Block with $1 \mathrm{ml} 5 \%$ goat serum in $0.2 \%$ saponin $1 \times \mathrm{PBS}$ for $1 \mathrm{~h}$ at room temperature.

8. Aspirate off blocking solution and apply $500 \mu \mathrm{l}$ diluted primary antibody (1x PBS, $0.2 \%$ saponin), incubate overnight at $4{ }^{\circ} \mathrm{C}$. 
Note: ER-HA-mNG21-10 and Sec61ß-HA-mNG2 $2_{1-10}$ localization can be assessed using anti-HA antibody (diluted 1:500).

9. Rinse three times with $1 \mathrm{ml} 1 \mathrm{x}$ PBS $+0.2 \%$ saponin for 3-5 min each time.

10. Apply $500 \mu \mathrm{l}$ diluted secondary Alexa Fluor antibody (1x PBS, $0.2 \%$ saponin) for $1 \mathrm{~h}$ at room temperature.

Note: Goat anti-rat Alexa Fluor 488 secondary antibody was applied at 1:500.

11. Rinse twice with $1 \mathrm{ml} 1 \times$ PBS $+0.2 \%$ saponin and once with $1 \mathrm{ml} 1 \times$ PBS for 3-5 min.

12. Mount coverslip face down on slide using mountant and allow to cure overnight at room temperature protected from light.

Note: For long-term storage, store slides at $4{ }^{\circ} \mathrm{C}$ protected from light.

13. Slides can be assessed by confocal imaging according to the manufacturer's operation manual.

D. Flow cytometry

Note: Perform the following cell culture steps in a biosafety cabinet.

1. Retrograde transport assessed by flow cytometry can be adapted based on your experimental conditions.

Note: Poorly maintained cells will affect retrograde trafficking. Use cells between 2 and 3 days since the last passage.

2. Adherent Cells:

a. Plate 24 -well plate to obtain $\sim 80 \%$ confluency or experimental conditions necessary pertaining to your experiment.

b. The next day, aspirate and replace with fresh growth media.

c. Add $20 \mathrm{~nm}$ CTB-mNG2 11 . Working 100x concentration of CTB-mNG2 11 can be prepared using serum free media or $1 \times$ PBS and kept on ice. Use within $24 \mathrm{~h}$ for each aliquot.

d. Incubate cells at $37^{\circ} \mathrm{C}, 5 \% \mathrm{CO}_{2}$ for $4-6 \mathrm{~h}$ if testing for the first time.

e. Wash cells, trypsinize cells and add FACS buffer and transfer to an Eppendorf or flow cytometry test tube. Keep cells on ice and process quickly. Alternatively, cells can be fixed with 4\% PFA for 20 min, washed and resuspend in FACS buffer. PFA fixation will help sustain the GFP signal.

Note: We have not noticed trypsinization to grossly effect final overall fluorescent signal but quick processing of samples by chilling on ice or fixation is recommended.

3. Suspension Cells:

a. Count cells to $1 \times 10^{5}-5 \times 10^{5} \mathrm{cells} / \mathrm{ml}$ and transfer $0.5 \mathrm{ml} / \mathrm{condition}$ into round bottom 96well deep-well plates. Cell density and volumes can be adjusted based on cell-line and experimental interest.

b. Add 20 nm CTB-mNG211. 100x Working concentration of CTB-mNG2 11 can be prepared from stock aliquots using serum free media or $1 x$ PBS. Protein is kept on ice before use. Use proteins within $24 \mathrm{~h}$ of thawing.

c. Incubate cells at $37^{\circ} \mathrm{C}, 5 \% \mathrm{CO}_{2}$ for $4-6 \mathrm{~h}$ if testing for the first time. 
d. Spin down cells, wash with 1xPBS and resuspend in FACS buffer. Fix cells as above if desired.

4. Cells can be passed through a $40 \mu \mathrm{m}$ strainer for single-cell suspension if an issue.

5. Vortex briefly and perform flow cytometry with the BD LSRFortessa ${ }^{\mathrm{TM}}$ Flow cytometer system according to the manufacturer's operation manual and experimental needs.

\section{Data analysis}

1. Chromatograms can be recorded using Chromlab $^{\mathrm{TM}}$ software and data plotted using GraphPad Prism.

2. Flow cytometry data can be analyzed by FlowJo Software:

a. Exclude dead cells and cell doublets from the analysis.

b. Position fluorescence positive gates relative to mock-treated cells for all flow experiments.

c. Normalization between different experimental conditions or comparing between cell lines such as wildtype and knockdown or knockout lines can be normalized based on total loading of the toxin using fluorescently labeled CTB-Alexa Fluor 488. Treat cells with 2 nM CTBAlexa Fluor 488 for each unique condition tested. Data normalization is then performed using cells treated with CTB-mNG2 ${ }_{11}$ normalized to CTB-Alexa Fluor 488 fluorescent signal for the identical condition.

3. Significance can be assessed using two-tailed $t$-test with $<0.05$ as significant. Graphs can be generated using GraphPad Prism.

4. For a complete experiment, a few conditions can be considered. One condition that should be present in every experiment is mock treated cells which will provide the background fluorescent signal. A second condition should use cells treated with CTB-Alexa Fluor 488 to determine maximum positive green fluorescence signal. Small molecule compounds may have inherent green fluorescence and thus contribute to background fluorescence. Compound treated only cells should thus be used at least initially to check for background fluorescence.

5. Some cell lines may not robustly provide strong retrograde signal possibly due to intrinsic trafficking biology of the cell or lack of toxin binding. Treatment of cells with CTB-Alexa Fluor 488 will help determine the maximum degree of toxin uptake.

6. Initial incorporation of this assay system to your group may begin with validated cell lines where the reporter system has robustly worked including COS7, K562 and HEK293T. The validated lines can also be used for initial quality control of purified recombinant split reporter toxins and technical training of the assay.

\section{$\underline{\text { Recipes }}$}

1. $100 \mathrm{mg} / \mathrm{ml}(1,000 \mathrm{x})$ ampicillin stock $(10 \mathrm{ml})$

$1 \mathrm{~g}$ Ampicillin 
$10 \mathrm{ml}$ Milli-Q water

2. $50 \mathrm{mg} / \mathrm{ml}(1,000 \mathrm{x})$ kanamycin stock $(10 \mathrm{ml})$

$0.5 \mathrm{~g}$ Kanamycin

$10 \mathrm{ml}$ Milli-Q water

3. LB agar plate

$24 \mathrm{~g} \mathrm{LB}$ agar

$650 \mathrm{ml}$ Milli-Q

Autoclave for $15-20 \mathrm{~min}$

Once sufficiently cool, add $100 \mu \mathrm{g} / \mathrm{ml}$ (1x) ampicillin, $50 \mu \mathrm{g} / \mathrm{ml}$ (1x) kanamycin

Pour into Petri-dishes and allow to set at room temperature

Store at $4{ }^{\circ} \mathrm{C}$

4. LB media (100 ml)

$2.5 \mathrm{~g}$ LB media

$100 \mathrm{ml}$ Milli-Q water

Autoclave for $15-20 \mathrm{~min}$

Just before use, add $100 \mu \mathrm{g} / \mathrm{ml}$ (1x) ampicillin or $50 \mu \mathrm{g} / \mathrm{ml}$ (1x) kanamycin

5. 2x YT media (100 ml)

$100 \mathrm{ml}$ Milli-Q water

Autoclave for $15-20 \mathrm{~min}$

Once sufficiently cool, add $100 \mu \mathrm{g} / \mathrm{ml}$ (1x) ampicillin

6. $1 \mathrm{M}$ IPTG stock solution $(10 \mathrm{ml})$

$2.38 \mathrm{~g} \mathrm{IPTG}$

$10 \mathrm{ml}$ Milli-Q water

Aliquot and store at $-20^{\circ} \mathrm{C}$

7. $50 \%$ glycerol $(100 \mathrm{ml})$

$50 \mathrm{ml}$ glycerol

$50 \mathrm{ml}$ Milli-Q water

Autoclave 15-20 min

8. Triton $\mathrm{X}-100$ lysis buffer

$10 \mathrm{mM}$ Tris $\mathrm{pH} 8.0$

$100 \mathrm{mM} \mathrm{NaCl}$

$0.5 \%$ Triton $\mathrm{X}-100$

$1 \mathrm{mM}$ PMSF

Store at $4{ }^{\circ} \mathrm{C}$

9. Binding buffer

$10 \mathrm{mM}$ Tris $\mathrm{pH} 8.0$

$100 \mathrm{mM} \mathrm{NaCl}$

Store at $4{ }^{\circ} \mathrm{C}$

10. Elution buffer 
$50 \mathrm{mM}$ Tris pH 8.0

$10 \mathrm{mM}$ L-Glutathione reduced

Milli-Q water

Make new before use

11. Dialysis Buffer

$10 \mathrm{mM}$ Tris $\mathrm{pH} 8.0$

$100 \mathrm{mM} \mathrm{NaCl}$

Store at $4{ }^{\circ} \mathrm{C}$

12. Buffer $A$

$5 \mathrm{mM} \mathrm{Na}_{2} \mathrm{HPO}_{4} \mathrm{pH} 7$

Filter and degas by applying a vacuum

Store at $4{ }^{\circ} \mathrm{C}$

13. Buffer $B$

$5 \mathrm{mM} \mathrm{Na}_{2} \mathrm{HPO}_{4} \mathrm{pH} 7$

$1 \mathrm{M} \mathrm{NaCl}$

Filter and degas by applying a vacuum

Store at $4{ }^{\circ} \mathrm{C}$

14. K562 cell media

RPMI

$10 \%$ FBS

$1 \%$ pen/strep

15. HEK 293T and COS7 cell media

\section{DMEM}

\section{$10 \%$ FBS}

$1 \%$ pen/strep

16. Blasticidin stock

$5 \mathrm{mg} / \mathrm{ml}$ in water

17. $4 \%$ paraformaldehyde (PFA)

$10 \mathrm{ml} 20 \%$ PFA

$40 \mathrm{ml} 1 \mathrm{x}$ PBS

18. $0.2 \%$ saponin

$0.2 \mathrm{~g}$ saponin

$10 \mathrm{ml}$ 1x PBS

19. FACS Buffer

$1 \times$ PBS

$2 \%$ FBS 


\section{Acknowledgments}

The work was supported by the Crohn's and Colitis Foundation of America and Rubin-Wolpow Fellowship (Boston Children's Hospital). National Institute of Health grants T32HD007466, DK048106 and DK084424. We acknowledge the previously published protocols from Luong et al. (2020) based on which current protocol was modified.

\section{Competing interests}

The authors declare no competing interest.

\section{References}

1. Chinnapen, D. J., Hsieh, W. T., te Welscher, Y. M., Saslowsky, D. E., Kaoutzani, L., Brandsma, E., D'Auria, L., Park, H., Wagner, J. S., Drake, K. R., Kang, M., Benjamin, T., Ullman, M. D., Costello, C. E., Kenworthy, A. K., Baumgart, T., Massol, R. H. and Lencer, W. I. (2012). Lipid sorting by ceramide structure from plasma membrane to ER for the cholera toxin receptor ganglioside GM1. Dev Cell 23(3): 573-586.

2. Cho, J. A., Chinnapen, D. J., Aamar, E., te Welscher, Y. M., Lencer, W. I. and Massol, R. (2012). Insights on the trafficking and retro-translocation of glycosphingolipid-binding bacterial toxins. Front Cell Infect Microbiol 2: 51.

3. De Luca, H. E. and Lencer, W. I. (2006). A biochemical method for tracking cholera toxin transport from plasma membrane to Golgi and endoplasmic reticulum. Methods Mol Biol 341: 127-139.

4. Falguieres, T., Mallard, F., Baron, C., Hanau, D., Lingwood, C., Goud, B., Salamero, J. and Johannes, L. (2001). Targeting of Shiga toxin B-subunit to retrograde transport route in association with detergent-resistant membranes. Mol Biol Cell 12(8): 2453-2468.

5. Feng, S., Sekine, S., Pessino, V., Li, H., Leonetti, M. D. and Huang, B. (2017). Improved split fluorescent proteins for endogenous protein labeling. Nat Commun 8(1): 370.

6. Johannes, L. and Popoff, V. (2008). Tracing the retrograde route in protein trafficking. Cell 135(7): 1175-1187.

7. Lencer, W. I. and Tsai, B. (2003). The intracellular voyage of cholera toxin: going retro. Trends Biochem Sci 28(12): 639-645.

8. Luong, P., Li, Q., Chen, P. F., Wrighton, P. J., Chang, D., Dwyer, S., Bayer, M. T., Snapper, S. B., Hansen, S. H., Thiagarajah, J. R., Goessling, W. and Lencer, W. I. (2020). A quantitative single-cell assay for retrograde membrane traffic enables rapid detection of defects in cellular organization. Mol Biol Cell 31(7): 511-519.

9. Personnic, N., Barlocher, K., Finsel, I. and Hilbi, H. (2016). Subversion of retrograde trafficking by translocated pathogen effectors. Trends Microbiol 24(6): 450-462. 
10. Rapak, A., Falnes, P. O. and Olsnes, S. (1997). Retrograde transport of mutant ricin to the endoplasmic reticulum with subsequent translocation to cytosol. Proc Natl Acad Sci U S A 94(8): 3783-3788.

11. Sandvig, K., Garred, O., Prydz, K., Kozlov, J. V., Hansen, S. H. and van Deurs, B. (1992). Retrograde transport of endocytosed Shiga toxin to the endoplasmic reticulum. Nature 358(6386): 510-512.

12. Torgersen, M. L., Skretting, G., van Deurs, B. and Sandvig, K. (2001). Internalization of cholera toxin by different endocytic mechanisms. J Cell Sci 114(Pt 20): 3737-3747.

13. Williams, J. M. and Tsai, B. (2016). Intracellular trafficking of bacterial toxins. Curr Opin Cell Biol 41: $51-56$.

14. Zhang, J. H., Chung, T. D. and Oldenburg, K. R. (1999). A simple statistical parameter for use in evaluation and validation of high throughput screening assays. J Biomol Screen 4(2): 67-73. 